\title{
Robotic synchronous treatment of colorectal cancer and liver metastasis: state of the art
}

\author{
Anita Sammarco', Nicola de'Angelis² ${ }^{1}$, Mario Testini', Riccardo Memeo ${ }^{3}$ \\ 'Department of Biomedical Sciences and Human Oncology, Unit of Endocrine, Digestive and Emergency Surgery, University \\ Medical School of Bari, Bari 70121, Italy. \\ ${ }^{2}$ Department of Digestive and Hepato-Pancreato-Biliary Surgery, Henri Mondor University Hospital, AP-HP, Université Paris-Est \\ Créteil (UPEC), Créteil 94010, France. \\ ${ }^{3}$ Department of Emergency and Organ Transplant, Institute of General Surgery and Liver Transplantation, University of Bari, Bari \\ 70124 , Italy.
}

\begin{abstract}
Correspondence to: Dr. Riccardo Memeo, Department of Emergency and Organ Transplant, Policlinico di Bari, Bari 70100, Italy. E-mail:drmemeo@yahoo.it
\end{abstract}

How to cite this article: Sammarco A, de'Angelis N, Testini M, Memeo R. Robotic synchronous treatment of colorectal cancer and liver metastasis: state of the art. Mini-invasive Surg 2019;3:31. http://dx.doi.org/10.20517/2574-1225.2019.33

Received: 2 Sep 2019 First Decision: 2 Sep 2019 Revised: 9 Oct 2019 Accepted: 9 Oct 2019 Published: 25 Oct 2019

Science Editor: Giulio Belli Copy Editor: Cai-Hong Wang Production Editor: Jing Yu

\begin{abstract}
Aim: To analyze the series in literature of pure robotic surgery.

Methods: A complete review of the literature was performed to identify papers with data concerning robotic synchronous treatment of colorectal liver metastases.
\end{abstract}

Results: Three papers demonstrate the feasibility of this kind of synchronous treatment.

Conclusion: Robotic synchronous treatment of primary tumor and colorectal liver metastasis is feasible and safe.

Keywords: Robotic liver surgery, minimally invasive liver surgery, liver surgery, hepatectomy, colorectal liver metastasis

\section{INTRODUCTION}

Colorectal cancer (CRC) remains the third cause of cancer in the United States, and liver is considered the most common site of metastasis. Surgical management of patients with primary CRC with liver metastasis

\footnotetext{
(c) () T) The Author(s) 2019. Open Access This article is licensed under a Creative Commons Attribution 4.0 International License (https://creativecommons.org/licenses/by/4.0/), which permits unrestricted use, sharing, adaptation, distribution and reproduction in any medium or format, for any purpose, even commercially, as long as you give appropriate credit to the original author(s) and the source, provide a link to the Creative Commons license, and indicate if changes were made.
} 
is still controversial with different opinion on the subject ${ }^{[1]}$. In patients with resectable disease, surgical resection can be considered the only potentially curative treatment even if operative sequence on the management of CRC and liver metastasis (CLM) still remain unclear ${ }^{[2]}$. Considering that $20 \%-40 \%$ of all patients with CRC presents at the time of diagnosis, two main strategies are available for patients with synchronous metastasis, treating primarily the liver (liver first) or the colon (colon first). In some cases, especially in case of oligometastatic lesion of the liver, considering the spread of parenchymal sparing surgery $^{[3]}$, it has been demonstrated that synchronous treatment could be considered a safe option, with acceptable morbidity and mortality ${ }^{[2]}$. Initially, the introduction of minimally invasive surgery (MIS) has probably limited synchronous metastasis treatment due to the technical difficulties of two different kind of resection. Despite this, nowadays, various studies have demonstrated the feasibility of MIS for synchronous liver and $\mathrm{CRC}^{[4]}$. With the introduction of robotic surgery, it represent a valid alternative lo laparoscopic surgery achieve optimal surgical and oncological outcomes. Considering robotic surgery, The well-known advantages of for laparoscopic surgery are preserved (shorter length of stay, reduced blood loss and postoperative morbidity) adding the advantages of robotic ${ }^{[5-8]}$ (magnified $3 \mathrm{~d}$ dimensional vision, a very good access allowed for posterosuperior segment's lesions or in contact with main liver vessels, less development of adhesions, tremor suppression, flexibility of the instruments).

The aim of this study is to present a systematic review of the literature to present the results of robotic surgery for colorectal liver metastasis in terms of short and long terms results.

\section{METHODS}

The present study was designed following the PRISMA guidelines.

A systematic literature search was performed by two authors (Sammarco A, Memeo R) using PubMed, EMBASE, Scopus and Cochrane Library Central restricting to papers in English language, finding studies and articles published from 1998 to 2018, focusing the study on the synchronized treatment of the liver metastasis and the CRC. All studies including patients who underwent robotic liver resection for colorectal liver metastasis were considered as eligible for the study, especially studies who considered synchronous pure robotic resection of CLM and CRC.

The following MESH search in heading were used: "robotic", "robot-assisted", "minimally invasive", "liver metastasis", "colorectal cancer", "stage 4", "combined resection", "simultaneous resection", and "synchronous resection".

All series containing other liver resection for different pathologies were excluded.

\section{RESULTS}

We retrospectively reviewed collected data included OT, perioperative blood loss, disease free, overall survival. We identified 16 relevant articles, to analyse the role of the MIS in patients with colorectal liver metastases (CRLM) and previous or synchronous surgery, focusing our attention on robotic assisted surgery (RAS). Just three of this 16 concerned CRLM only.

\section{CRLM and RAS}

Actually in literature, due to the reduced number of series describing RAS liver resection, most series comprehend different kind of pathology, mostly hepatocellular carcinoma and CRLM. Only 3 series described detailed results with only CRLM [Table 1] ${ }^{[9-11]}: 2$ were retrospective and 1 prospective The number of patients ranged from 6 to 59. No data were available on number of resected lesions. Only one series presented major resection: 1 left hepatectomy, 3 right hepatectomy in a total of 82 resected patients 


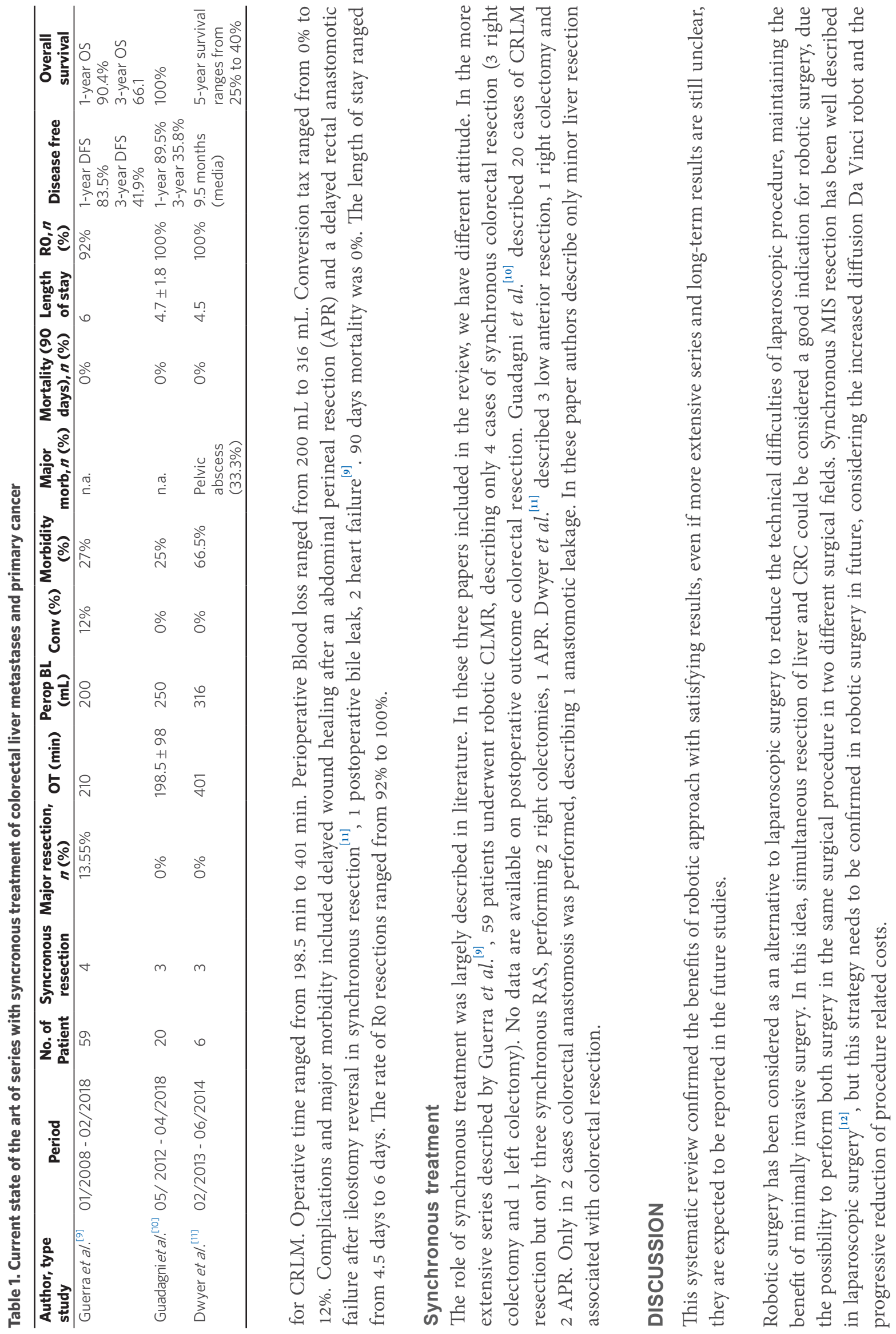


One of the main data available reading this review, is the pauperism of cases of synchronous resection. Only few series described resection for colorectal liver metastasis, most of them described as wedge resection. In all literature, only 8 case on 85 describe simultaneous resection, demonstrating that the synchronous approach still remains limited to few cases, despite the technical advantage of robotic surgery. As described in our paper, few synchronous procedure were performed, with two main limitations evidenced by the data, evidencing the difficulties to perform synchronous resection with major hepatectomies (only one series describe 13.5\% of major resection) and to perform colorectal anastomosis, due to the higher risk of anastomotic leak in patients who underwent pedicle clamping for control of bleeding during liver resection.

In synchronous resection, usually liver resection anticipates colon resection. The management of bleeding remains a priority in this kind of resection and prolonged portal vein occlusion should be avoided in order to reduce the risk of damage the colonic anastomosis ${ }^{[6,13]}$ : the prolonged vascular clamping leads to the transient portal hypertension with edema of the intestinal mucosa, responsible of the colorectal anastomotic failure ${ }^{[14]}$, so the use of the intermittent Pringle's maneuver has to be carefully shrewd.

Another important data evidenced by review is that despite an augmented duration of surgery due to the necessity to perform synchronous operation, operative time still remains acceptable and comparable to laparoscopic, non-impacting the length of stay.

Conversion rate still remains low, comparable to laparoscopic series ${ }^{[15]}$, confirming how the augmented dexterity probably associated to the high selection of patients guarantee a reduced rate of conversion.

Postoperative morbidity and mortality are acceptable, confirming the data reported by minimally invasive surgery. In the series of Dwyer et al. ${ }^{[11]}$, an anastomotic leakage is described, and this event strongly impact postoperative course due to the necessity of reoperation, questioning the risk of performing the colorectal anastomosis during synchronous resection.

Even if more studies are still required to define the oncologic outcome, RAS seems also expendable in a one-stage minimally invasive approach for the treatment of the simultaneous resection of primary colorectal neoplasm with synchronous liver metastases, showing advantages over conventional surgery in terms of postoperative short-term couse ${ }^{[14]}$.

Nowadays, the benefit of the robotic approach on the laparoscopic one is still a matter of debate, because of the heterogeneity of patients and the lack of long-term outcomes. This paucity of data makes difficult to draw a conclusion but, based on the few data available in this review, synchronous robotic liver and colic resection seems feasible in highly selected cases.

\section{DECLARATIONS}

\section{Authors' contributions}

Contributed to the concept and writing of the paper: Sammarco A

Contributed to the writing and revision of the paper: de'Angelis N, Testini M

Contributed to the writing and editing of the paper: Memeo $\mathrm{R}$

\section{Availability of data and materials}

Not applicable.

\section{Financial support and sponsorship}

None. 


\section{Conflicts of interest}

All authors declared that there are no conflicts of interest.

\section{Ethical approval and consent to participate}

Not applicable.

\section{Consent for publication}

Not applicable.

\section{Copyright}

(c) The Author(s) 2019.

\section{REFERENCES}

1. Zhang XL, Liu RF, Zhang D, Zhang YS, Wang T. Laparoscopic versus open liver resection for colorectal liver metastases: a systematic review and meta-analysis of studies with propensity score-based analysis, Int J Surg 2017;44:191-203.

2. Fretland ÅA, Dagenborg VJ, Bjørnelv GMW, Kazaryan AM, Kristiansen R, et al. Laparoscopic versus open resection for colorectal liver metastases: the OSLO-COMET randomized controlled trial. Ann Surg 2018;267:199-207.

3. Memeo R, De Blasi V, Adam R, Goéré D, Azoulay D, et al. Parenchymal-sparing hepatectomies (PSH) for bilobar colorectal liver metastases are associated with a lower morbidity and similar oncological results: a propensity score matching analysis. HPB (Oxford) 2016;18:781-90.

4. Thome S, Goswami J, Han K, Chidi AP, Geller DA, et al. Minimally invasive resection of colorectal carcer liver metastases leads to an earlier initation of chemotherapy compared to open surgery. J Gastrointest Surg 2015;19:2199-206.

5. Giulianotti PC. Totally robotic right hepatectomy. Arch Surg 2011;146:844.

6. Casciola L, Patriti A, Ceccarelli G, Bartoli A, Ceribelli C, et al. Robot-assisted parenchymal-sparing liver surgery including lesions located in the posterosuperior segments. Surg Endosc 2011;25:3815-24.

7. Croner RS, Perrakis A, Brunner M, Matzel KE, Hohenberger W. Pioneering robotic liver surgery in germany: first experiences with liver malignancies. Front Surg 2015;2:18.

8. Lai EC, Tang CN, Li MK. Robot-assisted laparoscopic hemi-hepatectomy: technique and surgical outcomes. Int J Surg 2012;10:11-5.

9. Guerra F, Guadagni S, Pesi B, Furbetta N, Di Franco G, et al. Outcomes of robotic liver resections for colorectal liver metastases. A multi-institutional analysis of minimally invasive ultrasound-guided robotic surgery. Surg Oncol 2019;28:14-8.

10. Guadagni S, Furbetta N, Di Franco G, Palmeri M, Gianardi D, et al. Rpbotic-assisted surgery for colorectal liver metastasis: a singlecentre experience. J Minim Access Surg 2019; doi: 10.4103/jmas.JMAS 26518.

11. Dwyer RH, Scheidt MJ, Marshall JS, Tsoraides SS. Safety and efficacy of synchronous robotic surgery for colorectal cancer with liver metastases. J Robot Surg 2018;12:603-6.

12. Cipriani F, Rawashdeh M, Stanton L, Armstrong T, Takhar A, et al. Propensity score-based analysis of outcomes of laparoscopic versus open liver resection for colorectal metastases, Br J Surg 2016;103:1504-12.

13. Patriti A, Ceccarelli G, Bartoli A, Spaziani A, Lapalorcia LM, et al. Laparoscopic and robot-assisted one-stage resection of colorectal cancer with synchronous liver metastases: a pilot study. J Hepatobiliary Pancreat Surg 2009;16:450-7.

14. Garritano S, Selvaggi F, Spampinato MG. Simultaneous minimally invasive treatment of colorectal neoplasm with synchronous liver metastasis. Biomed Res Int 2016;2016:9328250.

15. Qiu J, Chen S, Chengyou D. A systematic review of robotic-assisted liver resection and meta-analysis of robotic versus laparoscopic hepatectomy for hepatic neoplasms. Surg Endosc 2016;30:862-75. 